\title{
Analysis on large-capacity storage battery discharge of intelligent energy-feedback device
}

\author{
Shunxin Liu, Hui Song, Zhenhua Wen \\ Zhengzhou university of Aeronautics, Zhengzhou ,China \\ e-mail:Isxcj@126.com
}

\begin{abstract}
Keywords: storage battery discharge; DSP; power system; PID
Abstract-The reliability of DC operating power is largely decided by the storage battery in power system. In order to satisfy large-capacity storage battery discharge demand and requirements for energy-saving and emission-reduction, a new intelligent battery discharging device that can feedback energy was designed. The device is introduced in details including the circuit structure, parameters design and control methods in this paper. The experimental results indicate that the device has a good discharge performance, small discharge ripples, good stability and reliability, convenient and visual monitoring, and a good engineering application value.
\end{abstract}

\section{Introduction}

The battery is, in many cases, the last line of defense against AC power outage for both power plant and substation in power system. The reliability of back up power systems is becoming an even greater issue with the requirement of uninterruptible power supply[1]. It follows that one of the most critical pieces of information required by users of batteries in these application areas is to keep the battery's capacity. In most time the batteries are always charged at a constant voltage continuously for the normal supply of electricity in the power system. This would result in anode plate passivating, increasing the internal resistance, lowering the battery capacity and reducing supply less time[2]. Therefore, in order to maintain the activity of batteries the batteries must be regularly discharged.

Discharge of batteries commonly used 10-hour constant current discharge mode, by monitoring the battery voltage to detect the battery's capacity and status. With the power system development, high-capacity battery batteries pack more and more widely applied [3]. In view of this, this article has designed a new DSP-based intelligent high-capacity battery discharging device that feedback energy. By the rational allocation of the main circuit parameters, use of appropriate control strategy, user-friendly man-machine interface design, the discharge device can carry out a reliable and stable discharge with on-line monitoring.

\section{Principle of system}

Principle schematic of battery discharge device is shown in Fig.1. Discharge DC current is converted to three-phase AC current by the three-phase inverter and feedback into the grid. Sampling control, PWM signal generation, phase-locked and data exchange is finished by DSP2812 of TI. As long as the value of the discharge current, discharge time, discharge cut-off voltage is entered into devices, battery discharge can be completed automatically. At the same time battery voltage can be automatically recorded, to achieve discharge process unattended. 


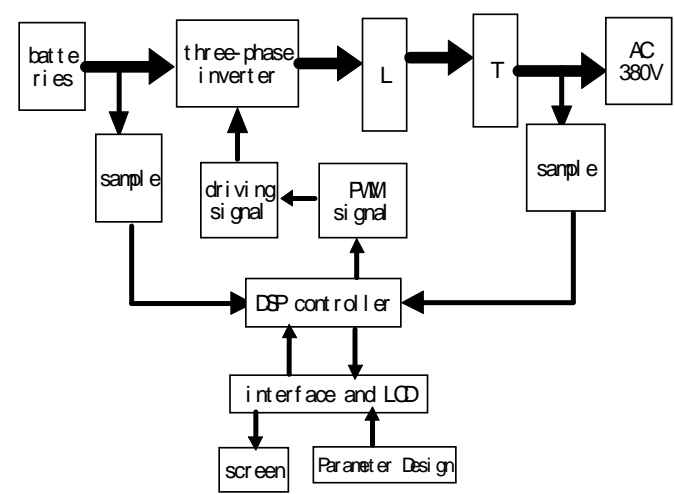

Fig. 1 Block diagram of system structure

\section{System Structure}

From Fig. 1 the system is mainly composed of the main circuit and control circuit, the following is a brief, respectively.

\section{Main circuit}

The main circuit of device is shown in Fig.2, about Insulated Gate Bipolar Transistor (IGBT) devices. The three-phase inverter is the core of main circuit. Inverter output is filtered by inductor, transformed and entered into the power grid [4] [5]. In the circuit there is a 250A battery discharge current and a 1:4 transformation ratio. Equation (1) is the calculation formula of the current. If the battery voltage is $230 \mathrm{~V}$ and three-phase power line voltage is $380 \mathrm{~V}$, the inverter output current for each phase will reach $349.5 \mathrm{~A}$ by (1).

$$
I=4 * 230 * 250 /(\sqrt{3} * 380)=349.5 A
$$

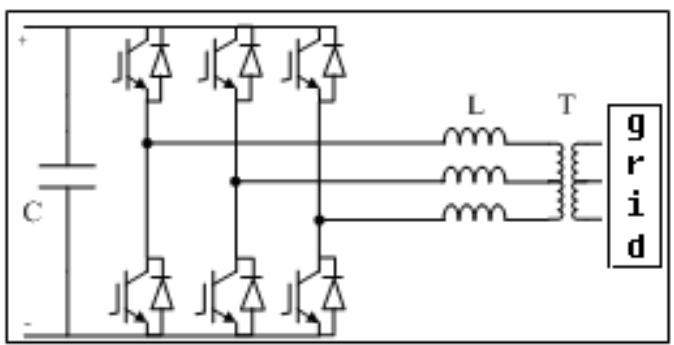

Fig.2 Structure diagram of main circuit

Selecting IGBT devices as well as the three-phase filter inductor, when taking into account economic considerations and the thermal design and structural design convenience, the FF400R06KE3 IGBT of EUPEC is a good choice to the main power circuit. DC side of two three-phase inverter is connected together. After a three-phase filter inductor in parallel the output is transformed and entered into the power grid.

Parameter Design

a) The parameters of DC side capacitors and the AC side filter inductance should be designed. Parameter Design of DC side capacitors are generally obtained according to empirical (2) [6]

$$
C_{d c} \geq \frac{\bar{p}}{2 \omega \cdot U_{d c} \cdot V_{r i p p}}=\frac{60000}{2 \times 314 \times 230 \times 10}=41540 \mu F
$$

In this case, the maximum voltage ripple is scaled to $10 \mathrm{~V}$; DC voltage is scaled to $230 \mathrm{~V}$. After simulation and trial, the real design parameter is selected $10450 \mathrm{~V} / 4700 \mathrm{uF}$ electrolytic capacitors in parallel.

Project supported by the zzia youth fund (2013061002)

$$
L \geq \frac{U_{d c}}{8 f_{c} \cdot \Delta I_{\max }}
$$


In this case, DC-Side Voltage is scaled to $230 \mathrm{~V}$, carrier frequency is scaled to $9.6 \mathrm{KHz}$, and ripple current is scaled to $10 \mathrm{~A}$. Through simulation and experimental verification, the actual design selected Three-phase AC filter inductance is $0.4 \mathrm{mH}$

Description of Control system

The control system diagram of the discharge device is shown in Fig.3. Control system is divided into two parts: digital phase-locked loop (PLL) and discharge current control. The transformation of abc-dq axis is theoretical foundation in these two parts. Fig. 4 shows the transformation[7].

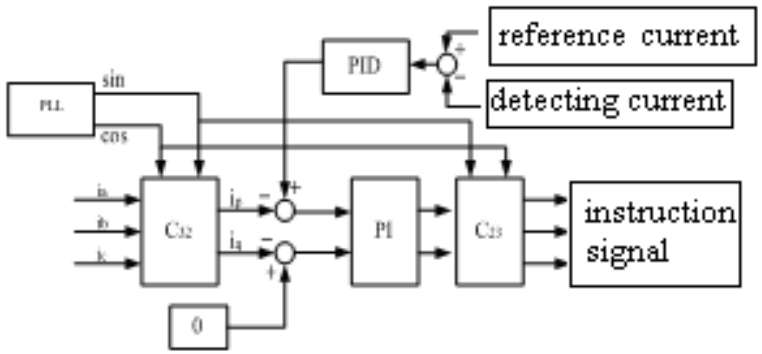

Fig.3 Block diagram of control structure

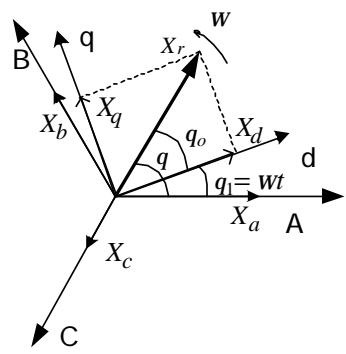

Fig.4 Transition diagram of abc and dq

According to the principle of equal vector space synthesis can be derived three-phase static abc coordinate system and synchronously rotating dq coordinate system transformation between the relationships:

$$
\begin{aligned}
T_{3 S / 2 d} & =\left[\begin{array}{lll}
\cos \omega t & \cos (\omega t-2 \pi / 3) & \cos (\omega t+2 \pi / 3) \\
-\sin \omega t & -\sin (\omega t-2 \pi / 3) & -\sin (\omega t+2 \pi / 3)
\end{array}\right] \\
T_{2 d / 3 S} & =\frac{2}{3}\left[\begin{array}{ll}
\cos \omega t & -\sin \omega t \\
\cos (\omega t-2 \pi / 3) & -\sin (\omega t-2 \pi / 3) \\
\cos (\omega t+2 \pi / 3) & -\sin (\omega t+2 \pi / 3)
\end{array}\right]
\end{aligned}
$$

Where $T_{3 S / 2 d}$ is transformation matrix from the three-phase static axis to the rotating coordinate and $T_{2 d / 3 S}$ is the reverse transformation matrix.

PLL control

Energy of feedback-type discharge device should be sent back to. It is required the same frequency and phase between the device output current and the grid. The device employs the digital phase-locked technology which is based on the instantaneous reactive power theory and the systems sequence voltage tracking technology. The principle is shown in Fig.5.

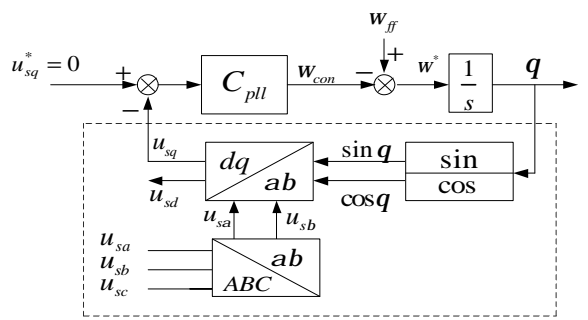

Fig.5 Structure of phase-lock control

When the grid voltage amplitude, that is, the amplitude of voltage vector synthesis $\stackrel{u}{s}_{s}$ keeps invariable, the weight of its q-axis reflects the d-axis and the grid voltage phase relationship [8]. 


\section{Conclusion}

As seen experimental results the intelligent energy-feedback device for large-capacity storage battery discharge on the basis of DSP and IGBT works without any problem. The device has shown a very good performance in power system. The device can enter discharge energy into the power grid, save energy and improve the discharge environment. Constant-current discharge can make it easy to accurately measure the capacity of the storage battery. Automatic controlling the course of the discharge and automatic recording the related data of the charge can make it possible to unattended operation. If necessary, efficiency of this system can be increased to discharge battery with high current.

\section{Acknowledgements}

The authors would like to thank the technical staff of the XUJI Power Group for the support given. Special thanks to L.S. Pan

for his technical support in the equipment usage and software installation

\section{References}

[1] Zalucki Z . Influence of current frequency on the dynamicvoltage/current characteristics of vacuumarcs[C]//International Symposium on Discharges and Electrical Insulation in Vacuum . Berkeley, USA : IEEE-DEIS , 1996 : 204-209

[2] D.K.Yue, "Battery Intelligent Constant-current Discharge System," Research \& Development, Vol.3, pp. 166-168, March, 2004.

[3] G.Hua, C.Leu, F.C.Lee, "Novel zero-voltage-transition PWM converters", Proc. Virginia Power Electronics Center Seminar, VPEC,pp.81-88, 1991.

[4] Z.F.Yan, X.J.Ma, S.G.Wei, "Research on a Novel Battery Constant Current Discharging Device," Journal of Academy of Arm ored Force Engineering, Vol.3,pp. 90-92, June, 2006.

[5] W.Z.Yao, S.B.Pan, Z.L.Li, Y.P.Yi, "Design of Battery Discharge Device Feeding Energy Back With Sine Wave Inverterm,” Power Electronics, Vol.2, pp. 10-12, April, 2004.

[6] Z.G.Gao, L.Wei, "Study on Control M ethod of 3-phase Voltage Type of PW M Rectifie," ElectricDrive forLocomatives, Vol.2,pp. 43-45, March, 2006.

[7] J.L.Zou, Z.X.Xu, Z.Y.Cao, "Battery Discharging Device Employing Variable-parameter PI," Power Electronics, Vol.4,pp. 9-11, April, 2003.

[8] L.W.Li, J.Y.Zou, "Design and Realization of Battery On-line Monitoring System," Research \& Development, Vol.11,pp. 7-9, Novembet, 2002. 